ORIGINAL ARTICLE

\title{
Histopathological Evaluation of Endoscopic Esophageal Biopsies
}

\author{
SHEEBA ISHTIAQ ${ }^{1}$, AYESHA GUL ${ }^{2}$, HINA UMAIR ${ }^{3}$ \\ ${ }^{1}$ Assistant Professor Histopathology, Gulab Devi Chest Hospital, Lahore \\ ${ }^{2}$ Senior Demonstrator Haematology, North West General Hospital and Research Center, Peshawar \\ ${ }^{3}$ Assistant Professor Physiology, Wah Medical College, Wah Cantt \\ Corresponding Author:Dr. Sheeba Ishtiaq, Email: sheeba_@@yahoo.com, Cell no.03408400060
}

\begin{abstract}
Background: Esophageal lesions have a wide range of clinical and pathologic spectrum. Understanding the endoscopic and pathologic features of esophageal lesions is critical for detecting, differentiating, and managing them. Esophageal lesions incidence might be neoplastic or non-neoplastic.

Aim: The current study aims to assess the clinical, endoscopic and histopathological evaluation of Esophageal Lesions.

Materials and Methods: The current cross-sectional study was conducted on 102 esophageal lesions received at the Pathology Department of Gulab Devi Chest Hospital, Lahore for the period during June 2020 to May 2021. Endoscopy was used to obtain esophageal biopsies of either gender, regardless of their age. Each case was microscopically evaluated, and biopsy specimens were immediately secured in $10 \%$ buffered neutral formalin. Data analysis and collection was done in SPSS version 21.

Results: Out of 102 endoscopic esophageal biopsies referred to Pathology Department for histopathological evaluation,male and female prevalence were $68(66.7 \%)$ and $34(33.3 \%)$ respectively. The overall mean age was $53.24 \pm 6.73$ with an age range from 21 to 80 years. Based on age, the patient's biopsies were categorized into six groups. A higher prevalence of esophageal lesions was observed in 51-60 (36.3\%) years followed by age group $61-70$ years $(23.5 \%)$. Of the 102 patient's biopsies,66 (64.7\%) biopsy revealed squamous cell carcinoma, squamous dysplasia cases were 12 (11.8\%), squamous papilloma was seen in one (0.98\%) case, Adenocarcinoma cases were 4 (3.9\%), Barrett's esophagus was 4 (3.9\%), esophagitis was 11 (10.8\%) and squamous epithelium only was present in $4(3.9 \%)$ cases.

Conclusion: Esophageal cancer is the common digestive tract malignancy. Malignancy can be distinguished from non-neoplastic masses on endoscopy by their symptoms, appearanceand size. For an early esophageal disease diagnosis, endoscopy is a popular and developed inspection means which can identify Barrett's esophagus and squamous dysplasia from malignant lesions, which can help in proper treatment and follow-up. Microscopic evaluation of lesions labeled as inflammatory on endoscopy can turn out to be malignant. This demonstrates the importance of microscopic examination as a confirmatory diagnostic tool. Accurate diagnosis can be carried out on microscopic examination with immunohistochemistry and histochemical stains.

Keywords: Esophagus; Epithelial lesions; Sub-epithelial lesions; Endoscopy
\end{abstract}

\section{INTRODUCTION}

Esophageal lesions have a wide range of clinical and pathologic spectrum. Understanding the endoscopic and pathologic features of esophageal lesions is critical for detecting, differentiating, and managing them. Esophageal lesions incidence might be neoplastic or non-neoplastic. Esophageal lesions in terms of pathological features and clinical progression have an assorted range of etiology. Dysphagia is rare in esophageal carcinomas. The proper treatment plan includes early detection, diagnosis, essential staging based on endoscopic findings. Esophageal malignant tumors account for less than $0.5 \%$ [1] while autopsy reports $20 \%$ of esophageal lesionsto be benign tumors [2]. Clinical attention has been given to esophageal lesions due to asymptomatic and tumor small size. Endoscopy with radiological findings could easily increase disease awareness and can detect esophageal lesions [3]. Dysplasia and sub-mucosal infiltration of the tumor cells are the histological basis of malignancy under the microscope, while endoscopically it relies on features of endoscopy such as raised, flat and cystic lesions. Globally esophageal lesion is a common pathological disorder among the world population in which common malignancy is squamous cell carcinoma [4]. In Pakistan, squamous cell carcinoma is among ten malignant neoplasms. The esophagus can have all kinds of benign pathological lesions which include Barrett's esophagus, candidiasis, squamous papilloma, reflux esophagitis, and esophageal atresia. All the biopsies can be accurately diagnosed based on endoscopy [5].

Esophageal cancer is well known for its wide variation on the basis of geographic area, ethnic group, and gender. Esophageal cancer can vary depending on regions throughout the world. Among global deaths caused by cancer, esophageal squamous cell carcinoma is the sixth common cause of worldwide mortality. It accounts for $83 \%$ of cases and $86 \%$ mortality rate in developing countries. A premalignant condition called as Barrett's esophagus (BE) is an acquired condition that is characterized by metaplastic replacement of normal squamous epithelium of the lower esophagus by columnar epithelium and goblet cells. One of the major risk factors for esophageal adenocarcinoma is Barrett's esophagus [6]. In Barrett's esophagus setting, the esophagus is raised and ulcerated from the tumor area while dysplastic mucosa of Barrett can be found near carcinoma in the lower esophagus. The present study describes the histopathological and endoscopic features with special stain assistance for Barrett's esophagus. Also, the esophagus of both malignant and benign are discussed [7-9]. 


\section{MATERIALS AND METHODS}

The current cross-sectional study was conducted on 102 esophageal lesions received at the Pathology department of Gulab Devi Chest Hospital, Lahore for the period during June 2020 to May 2021. Endoscopic biopsy was used to obtain esophageal lesions of either gender, regardless of their age. Ethical committee approved the study and Informed consent was obtained from each individual. Each case was microscopically evaluated, and biopsy specimens were immediately secured in $10 \%$ buffered neutral formalin. Absolute and graded alcohol of $50 \%, 70 \%$, and $80 \%$ were utilized for dehydration. Paraffin embedding with xylene was used for two steps of cleaning. Following the dewaxing, four micrometers thin sectionswere cut with stained hematoxylin and eosin stain. The specimen slides were immersed in the first and second xylene bath for their respective time duration of 3 and 2 minutes. Immersion in graded alcohol and rinsed in distilled water followed by hematoxylin staining and complete wash with running water. The special stains like PAS for fungal infections and AB/PAS for Barrett's esophagus were utilized for metaplastic changes investigation. This technique separates the combined AB/PAS with $\mathrm{PH} 2.5$ for acid and neutral mucins. Methanol was used for smear fixation and acid solution of periodic acids Schiff solution was oxidized. Dry slide mounting was done by DPX.

\section{RESULTS}

Out of 102 endoscopic esophageal biopsies referred to Pathology Department for Histopathological evaluation male and female prevalence were 68 (66.7\%) and 34 (33.3\%)respectively. The overall mean age was $53.24 \pm 6.73$ with an age range from 20 to 80 years. The patient's biopsies were divided into six groups based on their age. i.e. (21-30, 31-40, 41-50, 51-60, 61-70, 71-80) as shown in Table/Figure-1. A higher prevalence of esophageal lesions were observed in 51-60 (36.3\%) years followed by age group $61-70$ years (23.5\%). Of the 102 patients biopsies, $66(64.7 \%)$ biopsies revealed squamous cell carcinoma, squamous dysplasia cases were $12(11.8 \%)$, squamous papilloma was one $(0.98 \%)$ case, Adenocarcinoma cases were $4(3.9 \%)$, Barrett's esophagus was 4 (3.9\%), esophagitis was $11(10.8 \%)$ and squamous epithelium only were 4 (3.9\%) cases as shown in Table/Figure 2.

Table 1. Age wise distribution of 102 esophageal biopsies.

\begin{tabular}{|l|l|l|}
\hline Age Group & Frequency & Percentage (\%) \\
\hline $21-30$ & 3 & 2.8 \\
\hline $31-40$ & 6 & 5.9 \\
\hline $41-50$ & 21 & 20.6 \\
\hline $51-60$ & 37 & 36.3 \\
\hline $61-70$ & 24 & 23.5 \\
\hline $71-80$ & 11 & 10.9 \\
\hline Total & 102 & 100 \\
\hline
\end{tabular}

Table and Figure-3 demonstrates the prevalence of common esophageal endoscopic lesions diagnosed on microscopy with Squamous cell carcinoma (SCC) comprising about 66 (64.7\%) cases followed by squamous dysplasia $12(11.8 \%)$ cases. Adenocarcinoma cases were $4(3.9 \%)$, Barrett's esophagus was $4(3.9 \%)$, esophagitis was $11(10.8 \%)$ and squamous epithelium only was 4
(3.9\%) cases in male 61 (59.8) and female patients 41 $(40.2 \%)$. The male to female ratio was $1.49: 1$.

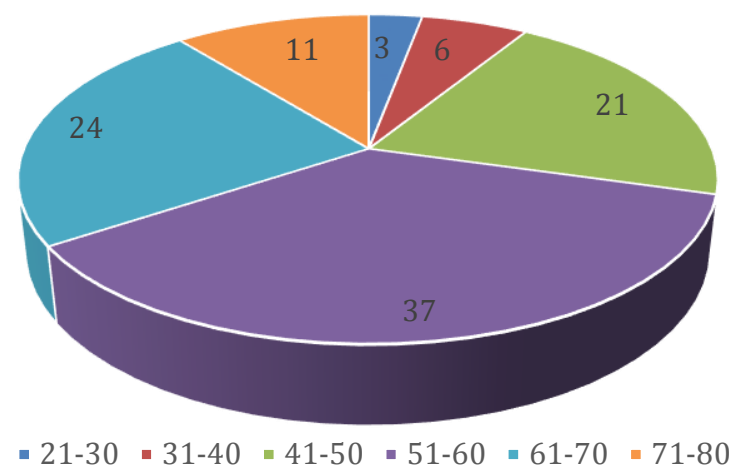

Figure-1 Age wise distribution of 102 esophageal lesions

Table 2. Microscopic findings of 102 endoscopic esophageal lesions.

\begin{tabular}{|l|l|l|}
\hline Features & Frequency $(\mathrm{n})$ & Percentage $(\%)$ \\
\hline Squamous cell carcinoma & 66 & 64.7 \\
\hline Squamous dysplasia & 12 & 11.8 \\
\hline Squamous papilloma & 1 & 0.99 \\
\hline Adenocarcinoma & 4 & 3.9 \\
\hline Barrett's esophagus & 4 & 3.9 \\
\hline Esophagitis & 11 & 10.9 \\
\hline Squamous epithelium only & 4 & 3.9 \\
\hline Total & 102 & 100 \\
\hline
\end{tabular}

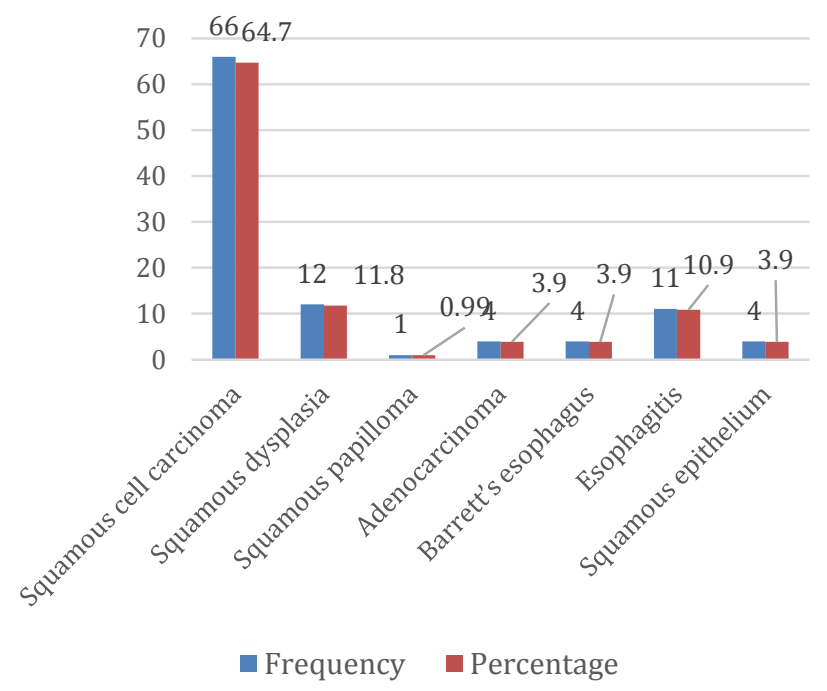

Figure-2. Microscopic findings of 102 endoscopic esophageal lesions

Table-3. Esophageal lesions in Male Patients $(n=61)$ and female $(\mathrm{n}=41)$ patients

\begin{tabular}{|l|l|l|l|}
\hline Lesions types & Male $\mathrm{n}(\%)$ & Female $\mathrm{n}(\%)$ & Total \\
\hline Barrett's Esophagus & $3(75)$ & $1(25)$ & $4(100)$ \\
\hline Squamous Dysplasia & $7(58.3)$ & $5(41.7)$ & $12(100)$ \\
\hline $\begin{array}{l}\text { Squamous cell } \\
\text { carcinoma }\end{array}$ & $47(71.2)$ & $19(28.8)$ & $66(100)$ \\
\hline Adenocarcinoma & $4(100)$ & $0(0)$ & $4(100)$ \\
\hline Total & 61 & 25 & 86 \\
\hline
\end{tabular}




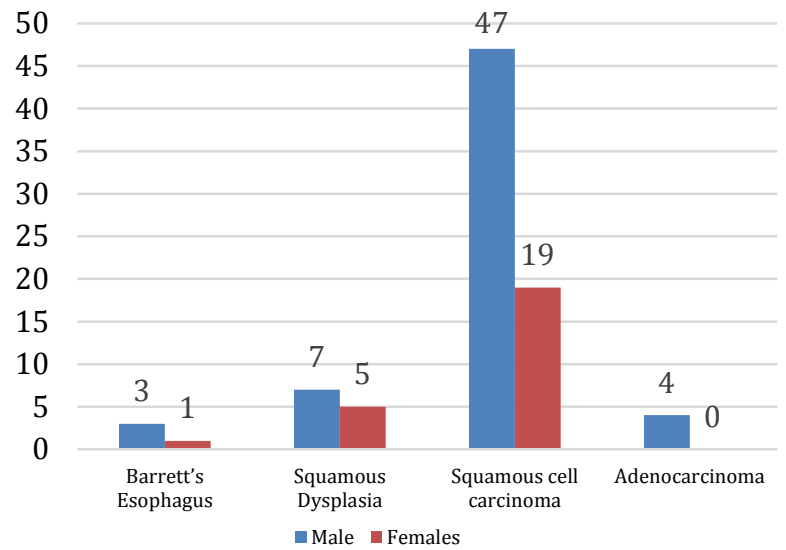

Figure-3. Esophageal lesions in Male Patients $(n=61)$ and female 41 patients

Endoscopic-based clinical presentation among 102 cases is highlighted in Table 4. These distributed cases involve loss of weight, dysphagia, anorexia, vomiting, heartburn,dyspepsia and food regurgitation.

Table-4 Highlights of Endoscopic-based clinical presentation among 102 cases

\begin{tabular}{|l|l|l|}
\hline Features & Frequency $(\mathrm{n})$ & Percentage $(\%)$ \\
\hline Dysphagia & 88 & 86.3 \\
\hline Loss of weight & 63 & 61.8 \\
\hline Anorexia & 61 & 59.8 \\
\hline Vomiting & 38 & 37.3 \\
\hline Heartburn & 42 & 41.2 \\
\hline Dyspepsia & 34 & 33.3 \\
\hline Food regurgitation & 83 & 81.4 \\
\hline
\end{tabular}

\section{DISCUSSION}

The present study investigated the 102 esophageal lesions routinely received at the pathology department. The specimen sections were stained in Eosin and Hematoxylin. For relevant cases, immunohistochemical stains, PAS, and another special stain like AB/PAS at $\mathrm{pH} 2.5$ were used. Of the total 102 cases, endoscopic cases were as follows; malignant lesion 61, malignancy suspicious 19, benign lesions 8, and esophagitis (infective and inflammatory pathology) 14 [10]. Out of 61 endoscopically malignant lesions, 59 (96.7\%) were microscopically malignant which comprised of 57 Squamous cell carcinoma and 2 cases of Adenocarcinoma. 2 cases become identified as Candida esophagitis that were confirmed via PAS stain. Thirteen instances of esophagitis had been identified endoscopically, out of which $12(92.31 \%)$ correlated with microscopic findings, which had been mentioned as Reflux esophagitis (6 cases), Candidiasis (3cases), Herpes simplex esophagitis (2 cases), Eosinophilic esophagitis (1 case). 1 case become identified as Squamous cell carcinoma. So one infective lesion on endoscopy,was diagnosed microscopically malignant lesion [11-14]. Out of 19 lesionsthat are suspicious for malignancy, squamous cell carcinoma was diagnosed in $8(42.1 \%)$ cases, squamous dysplasia 9 (52.3\%) and Adenocarcinoma in 2 (10.5\%) under the microscope. Endoscopically diagnosed eight cases of benign lesions turned out to be stratified squamous epithelium $4(57 \%)$ cases,squamous papilloma
$1(12 \%)$, and Hyperplastic polyp were diagnosed in 3 $(37.5 \%)$ cases. Barrett's esophagus was confirmed in 4 cases based on correlation with history and microscopic evaluation [15].

The most common neoplasm was Squamous cell carcinoma diagnosed in $66(64.7 \%)$ cases in our study. Similar findings were found in another study [16]. The prevalence of esophageal carcinoma in our study was more common in male compared to the female with male to female ratio of 1.8: 1.78. Tumors with increased mitotic activity, hyperchromasia, nuclear enlargement and no stromal invasion is called squamous dysplasia which is a precancerous lesion[17]. Another study found $14 \%$ prevalence of squamous dysplasia compared to $12 \%$ in our study as both findings approximately matched [18]. Previously diagnosed squamous cell dysplasia was found in squamous cell carcinoma combination. High and lower grade dysplasia was found in two cases and 9 cases respectively. Our findings matched another study [19].

The squamous papilloma found in one case with overlying mucosa and shows myxoid and thin-walled vessels exhibiting foci of fibrous mature core tissue. Two cases of hyperplastic polyps have been reported in gastroesophageal junction. In our study esophagitis was diagnosed in 12 cases which matched another study finding [20]. $M / F$ ratio was $5: 1$. The prevalence of esophagitis lesions was 2.5 per 1000 population reported by another study [21]. Reflux esophagitis was reported in 6 cases. Microscopic and endoscopic findings of esophagitis were reported in 12 cases like the other study [22]. In endoscopic findings, one infective esophagitis was diagnosed microscopically as squamous cell carcinoma .Therefore, for an accurate diagnosis, microscopic evaluation is mandatory. Another study reported a similar diagnosis of the immunocompetent individuals for herpes simplex esophagitis[23].

\section{CONCLUSION}

Esophageal cancer is the common digestive tract malignancy. Malignancy can be distinguished from nonneoplastic lesions by symptoms, appearance and size of lesions. For an early esophageal lesion diagnosis, endoscopy is a popular and developed inspection means which identify Barrett's esophagus and squamous dysplasia from malignant lesions for proper treatment and follow-up. Microscopic evaluation of infective lesions diagnosed on endoscopy can be malignant on microscopic examination. This demonstrates the importance of microscopic examination as a confirmatory diagnostic tool. Accurate diagnosis can be carried out on microscopic examination with immunohistochemical and special histochemical stains.

\section{REFERENCES}

1. Kumar EH, Parijatham BO, Srivastava V. Endoscopic Findings and Histopathological Correlation of Esophageal Lesions. Journal of Pharmaceutical Research International. 2021 Apr 5:1-0.

2. William K, Ovalle Patrick C. Nahirney netter's essential histology, second edition. 2020;278282.

3. Tadashi Terada. A clinic opathologic study of esophageal 860 benign and malignant lesions in 910 cases of 
consecutive esophageal biopsies. Int $\mathrm{J}$ ClinExpPathol. 2013;6(2):191-198.

4. Nomura, Y.; Moriichi, K.; Fujiya, M.; Okumura, T. The Endoscopic Findings of the Upper Gastrointestinal Tract in Patients with Crohn's Disease. Clin. J. Gastroenterol. 2017, 10, 289-296.

5. Sakuraba, A.; Iwao, Y.; Matsuoka, K.; Naganuma, M.; Ogata, H.; Kanai, T.; Hibi, T. Endoscopic and Pathologic Changes of the Upper Gastrointestinal Tract in Crohn's Disease. Biomed Res. Int. 2014, 2014, 610767.

6. So, H.; Ye, B.D.; Park, Y.S.; Kim, J.; Kim, J.S.; Moon, W.; Lee, K.M.; Kim, Y.S.; Keum, B.; Kim, S.E.; et al. Gastric Lesions in Patients with Crohn's Disease in Korea: A Multicenter Study. Intest. Res. 2016, 14, 60-68.

7. Johnson, C.M.; Hartman, D.J.; Ramos-Rivers, C.; Rao, B.B.; Bhattacharya, A.; Regueiro, M.; Schwartz, M.; Swoger, J.; Al Hashash, J.; Barrie, A.; et al. Epithelioid Granulomas Associate with Increased Severity and Progression of Crohn's Disease, Based on 6-Year Follow-Up. Clin. Gastroenterol. Hepatol. 2018, 16, 900-907.

8. Nikami T, Saito S, Tajiri $\mathrm{H}$. et al. The evaluation of histological atypia and depth of invasion of colorectal lesions using magnified endoscopy with narrow-band imaging. GastroenterolEndosc 2009; 51: 10-19

9. Hewett DG, Kaltenbach T, Sano Y. et al. Validation of a simple classification system for endoscopic diagnosis of small colorectal polyps using narrow-band imaging. Gastroenterology 2012; 143: 599-607

10. Hayashi N, Tanaka S, Hewett DG. et al. Endoscopic prediction of deep submucosal invasive carcinoma: validation of the narrow-band imaging international colorectal endoscopic (NICE) classification. GastrointestEndosc 2013; 78: 625-632.

11. Ebi M, Shimura T, Yamada T. et al. Multicenter, prospective trial of white-light imaging alone versus white-light imaging followed by magnifying endoscopy with narrow-band imaging for the real-time imaging and diagnosis of invasion depth in superficial esophageal squamous cell carcinoma. GastrointestEndosc 2015; 81: 1355-361.e1352

12. Lee MW, Kim GH, Hoseok I. et al. Predicting the invasion depth of esophageal squamous cell carcinoma: comparison of endoscopic ultrasonography and magnifying endoscopy. Scand J Gastroenterol 2014; 49: 853-861

13. Oyama $\mathrm{T}$, Inoue $\mathrm{H}$, Arima $\mathrm{M}$. et al. Prediction of the invasion depth of superficial squamous cell carcinoma based on microvessel morphology: magnifying endoscopic classification of the Japan Esophageal Society. Esophagus 2017; 14: 105-112

14. Yao K, Doyama H, Gotoda T. et al. Diagnostic performance and limitations of magnifying narrow-band imaging in screening endoscopy of early gastric cancer: a prospective multicenter feasibility study. Gastric Cancer 2014; 17: 669679

15. Uedo N, Fujishiro M, Goda K. et al. Role of narrow band imaging for diagnosis of early-stage esophagogastric cancer: current consensus of experienced endoscopists in AsiaPacific region. Digest Endosc 2011; 23: 58-71

16. Hirata M, Tanaka S, Oka S. et al. Magnifying endoscopy with narrow band imaging for diagnosis of colorectal tumors. GastrointestEndosc 2007; 65: 988-995

17. Sano Y, Hirata D, Saito Y. Japan NBI Expert Team classification: Narrow-band imaging magnifying endoscopic classification of colorectal tumors. Dig Endosc 2018; 30: 543-545

18. Komeda $\mathrm{Y}$, Kashida $\mathrm{H}$, Sakurai T. et al. Magnifying narrow band imaging (NBI) for the diagnosis of localized colorectal lesions using the Japan NBI Expert Team (JNET) classification. Oncology 2017; 93: 49-54

19. Sumimoto K, Tanaka S, Shigita K. et al. Clinical impact and characteristics of the narrow-band imaging magnifying endoscopic classification of colorectal tumors proposed by the Japan NBI Expert Team. GastrointestEndosc 2017; 85: 816-821

20. Sakamoto T, Nakajima T, Matsuda T. et al. Comparison of the diagnostic performance between magnifying chromoendoscopy and magnifying narrow-band imaging for superficial colorectal neoplasms: an online survey. GastrointestEndosc 2018; 87: 1318-1323

21. Nomura, Y.; Moriichi, K.; Fujiya, M.; Okumura, T. The Endoscopic Findings of the Upper Gastrointestinal Tract in Patients with Crohn's Disease. Clin. J. Gastroenterol. 2017, 10, 289-296.

22. Weinstein, T.; Valderrama, E.; Pettei, M.; Levine, J. Esophageal Crohn's Disease: Medical Management and Correlation between Clinical, Endoscopic, and Histologic Features. Inflamm. Bowel Dis. 1997, 3, 79-83.

23. Sakuraba, A.; Iwao, Y.; Matsuoka, K.; Naganuma, M.; Ogata, H.; Kanai, T.; Hibi, T. Endoscopic and Pathologic Changes of the Upper Gastrointestinal Tract in Crohn's Disease. Biomed Res. Int. 2014, 2014, 610767. 